\title{
Construção de sentido do texto literário: uma análise semiótica
}

\author{
Construction sense to literary text: a semiotic analysis
}

\section{Ernani Terra*}

Resumo: Este artigo, denominado "Construção de sentido do texto literário: uma análise semiótica", insere-se na linha de pesquisa Leitura do texto literário: fundamentos semióticos, desenvolvida pelo autor em nível de pós-doutoramento em semiótica discursiva e tem por objetivo mostrar a construção do sentido de textos literários com fundamento na semiótica de linha francesa. A metodologia empregada é a desmontagem e a remontagem de dois textos, um poema e um conto, num processo em que se analisam os três níveis do percurso gerativo do sentido. São também feitas relações com outros textos da autora. No nível fundamental, analisam-se os valores que serão assumidos por um sujeito e, posteriormente, discursivizados. No nível intermediário, o das estruturas narrativas, analisa-se o percurso do sujeito, que assume as axiologias, tornando o virtual (as axiologias) em valores atualizados. No nível mais superficial e concreto, o das estruturas discursivas, investiga-se a transformação do sujeito narrativo em ator, numa passagem do sujeito atualizado para um sujeito realizado. Nesse nível, investigam-se ainda as isotopias figurativas, responsáveis pela assunção que mais claramente expõem as determinações ideológicas. Os resultados obtidos mostram que o sentido dos textos se dá por um percurso que vai da decomposição do todo em fragmentos, que é negada, para a afirmação da totalidade.

Palavras-Chave: Texto literário. Construção de sentido. Semiótica discursiva.

\begin{abstract}
This article, entitled "Construction sense to literary text: A semiotic analysis", is part of the research line The reading of the literary text: semiotic Fundaments, developed by the author in post-doctoral level on discursive semiotics, which aims to show one direction construction of literary texts with basis on the semiotics of French Line. The methodology applied is the disassembly and the reassembly of two texts, a poem and a tale, in a process that analyzed three levels of generative route sense. There are also made relations with other texts of the author. In the fundamental level, we analyze the values to be assumed by a subject and subsequently act as speech. In intermediate level, of the narrative structures, we analyze the course of the subject, that take as axiologies, making them virtual (the axiologies) on updated values. In the surface and concrete level, about the level of \footnotetext{
Presbiteriana Mackenzie, onde desenvolve pesquisa, com fundamento na Semiótica Discursiva, sobre o discurso da interdição na obra Crônica da Casa Assassinada, de Lúcio Cardoso, sob a supervisão da Profa. Dra. Diana Luz Pessoa de Barros. E-mail: ernani@ernaniterra.com.br.
}

* Doutor em Língua Portuguesa pela Pontifícia Universidade Católica de São Paulo. Pós-doutorando na Universidade
\end{abstract}


the discursive structures, the transformation of the narrative subject in actor is investigated, passing from subject updated to subject accomplished. At that level, figurative isotopies are still investigated, which are responsible for the assumption that more clearly exposed the ideological determinations. The obtained results show the sense of texts happens through a route that goes from decomposition of the whole in fragments, whose decomposition is denied to affirm the totality.

Keywords: Literary text. Construction of meaning. Discursive semiotics.

No descomeço era o verbo. Só depois é que veio o delírio do verbo.

(Manoel de Barros)

\section{Considerações Iniciais}

Neste artigo, discuto, sob a ótica da semiótica discursiva de linha francesa, a produção literária de Jessyca Pacheco (2015). A metodologia é a análise de seu livro de estreia, Matéria derradeira, uma vez que pressupomos que 0 ator discursivo se manifesta pela totalidade de seus discursos, constituindo uma unidade não só actorial, mas também actancial. A partir dessa totalidade discursiva manifesta-se o ethos do ator, corporificado tanto na massa unificada de seus textos, quanto em cada unidade de texto. No entanto, dados os limites deste artigo, detenho-me mais exaustivamente em dois textos significativos da produção literária da autora, "Cicatriz" e "Fragmentos".

A partir da análise desses textos, procuro mostrar, utilizando os procedimentos do percurso gerativo, como proposto por A.J. Greimas, a construção do sentido dos textos e como o ator discursivo de Matéria derradeira se corporifica cada vez que se enuncia como um sujeito que assume valores que propõe ao enunciatário. Para tanto, abstraio o plano da expressão e detenho-me na análise dos níveis fundamental, narrativo e discursivo, mostrando como valores presentes no nível fundamental são assumidos por um sujeito no nível narrativo e, finalmente, manifestados no nível discursivo por meio de uma sintaxe e de uma semântica.

Em relação à sintaxe do discurso, discuto os procedimentos enunciativos, em especial a actorialização e a temporalização. Quanto à semântica discursiva, dedico atenção à figurativização como fonte de manifestação de valores. Os 
textos discutidos inserem-se num campo discursivo mais amplo, formado por todos os textos presentes no livro de estreia da autora.

Cada ocorrência enunciativa encadeia-se a outros atos de linguagem presentes no livro, um todo discursivo resultante de enunciações singulares, o que permite ler cada texto como uma singularidade ou como elo de uma cadeia de textos que se superpõem uns aos outros. Assim sendo, sempre que necessário estabeleço relações discursivas dos textos em análise com demais textos da autora.

A escolha pelo aparato teórico-metodológico da semiótica discursiva deveu-se, em primeiro lugar, ao fato de que é nessa área que desenvolvo pesquisas em nível de pós-doutorado. Em segundo lugar, por entender que essa teoria é a melhor que se presta à análise imanente dos textos e, conjugada aos estudos da enunciação, permite estabelecer as relações entre discurso e suas condições de produção e recepção.

\section{O corpus}

Para o presente artigo, escolhi o livro de estreia de Jessyca Pacheco, Matéria derradeira, lançado no segundo semestre de 2015. O livro apresenta trinta poemas e um texto em prosa, que pode ser enquadrado no gênero conto. Como assinalei, o ator discursivo decorre da totalidade de seus discursos, embora se construa em cada texto. Escolhi como textos-fonte para esta investigação o poema "Cicatriz" e o conto "Fragmentos", que serão aqui analisados sem perder de vista que se inserem num todo discursivo, representado por todos os textos presentes em Matéria derradeira, ou seja, a análise levará em conta aquilo que Barros (1988) denomina contexto interno, ou seja, a relação que os textos, objetos da análise, guardam com os demais textos da obra da autora. A justificativa para a escolha desses dois textos deveu-se ao fato de que, embora pertencentes a gêneros diferentes, apresentam o mesmo tema. Dada a pequena extensão dos textos, reproduzoos a seguir. 


\section{Cicatriz}

Corpo talhado, mudo, cansado

peso moribundo, pelo sangue de outros manchado.

Caminhar lento, grassento, passos leves como cimento

brancos os cabelos, ostento sombras a sussurrar no vento.

Dias de paz aniquilados, se perdem no caos, esviscerados.

Sobe o pano, cala-se o pranto, nasce o encanto

Fascínio pelo desumano, prazer leviano.

(PACHECO, 2015, p. 15).

\section{Fragmentos}

Antes, não existia nada. Nada além daquela fina poeira cinza que caía lentamente sobre seus fios brancos e lisos. Seus ouvidos zuniam como se um inseto houvesse se apoderado de seu corpo e nunca mais pretendesse deixar sua hospedeira. Era o único som além do ranger da madeira a cada nova investida de uma labareda jovem e indomável.

Ali parada, anestesiada, com seus tênis verdes e roídos, tentou lembrar se havia tirado as poucas peças de roupa do varal e a ideia de ficarem com aquele odor mórbido a deixou perturbada. Pensava em como se livrar desse odor enquanto seus olhos vidrados observavam como estrangeiros aquele cenário de natureza morta que exercia nela um fascínio fulminante.

As chamas aos poucos consumiam a cor e a forma de cada objeto; a cama simples de madeira mofada, os poucos quadros de fotografia que pendiam espalhados pela casa; os discos de vinil empoeirados que ninguém ouvia se contorciam em câmera lenta com o calor que se aproximava dos pratos de porcelana que jamais foram usados, do berço da criança esquecida em uma única imagem embotada, dos livros que não conseguiu salvar. Todos os pequenos resquícios de uma solidão compartilhada transformados em cinzas que cintilavam na luz do poste na rua agora tomada pelo calor e pelas pessoas que se acumulavam. 
As aglomerações desencantam. Toda a individualidade e o prazer da solidão desaparecem. Nunca gostou de aglomerações - pessoas grudadas umas nas outras com aquela mórbida curiosidade de quem tem tédio da vida - e logo que iniciaram o ritual ao redor da fogueira que se fez do que um dia foi a casa de sua juventude, ela vagarosamente se retirou esquecendo a roupa no varal, sai lentamente de cena, deixando pra trás a fétida silhueta que a cativou em uma tarde quente e fastidiosa de domingo. (PACHECO, 2015, p. 43-44).

\section{Pressupostos Téoricos}

A semiótica discursiva tem por objeto de estudo o texto. No dizer de Barros (2003, p. 7), "[...] procura descrever e explicar o que o texto diz e como ele faz para dizer o que diz". Sua preocupação é com o sentido do texto, o que faz com que, num primeiro momento, abstraia o plano da expressão, centrando sua análise no plano do conteúdo. Uma das vantagens dessa metodologia é o fato de a análise semiótica poder ser aplicada a qualquer texto, independemente da forma de expressão que assuma, seja uma pintura, um filme, uma peça teatral, um anúncio publicitário ou, como é o caso do que se investiga neste artigo, textos literários.

A semiótica discursiva, segundo Barros (1988, p. 13), "[...] tenta determinar as condições em que um objeto se torna objeto significante para 0 homem" e, na esteira de Saussure e Hjelmslev, "[...] não toma a linguagem como um sistema de signos, mas como um sistema de significações, ou melhor, de relações, pois a significação decorre da relação." (BARROS, 1988, p. 13). Para a semiótica, o sentido obedece a um percurso gerativo que vai de um nível mais simples e abstrato (o nível fundamental) a um nível mais concreto e superficial (o nível discursivo), havendo entre eles o nível narrativo. Cada um desses níveis apresenta uma sintaxe e uma semântica próprias. No fundamental, realizam-se as operações sintáticas a partir de uma categoria elementar, formada pela relação entre dois termos-objetos, pois um termo só não significa. No narrativo, uma sintaxe trata das relações entre sujeito e objeto, um simulacro da ação do homem no mundo, e uma semântica cuida 
dos valores de que são investidos os objetos. A semântica narrativa atualiza os valores presentes no nível fundamental, axiologizados como virtuais. $\mathrm{Na}$ conversão para o nível narrativo, as axiologias do nível fundamental são assumidas por um sujeito e transformadas em valores ideologizados.

O sintagma elementar da sintaxe narrativa é denominado programa narrativo (PN), que é representado por um enunciado de fazer que rege um enunciado de estado, que pode ser expresso da seguinte maneira:

\section{Programa narrativo}

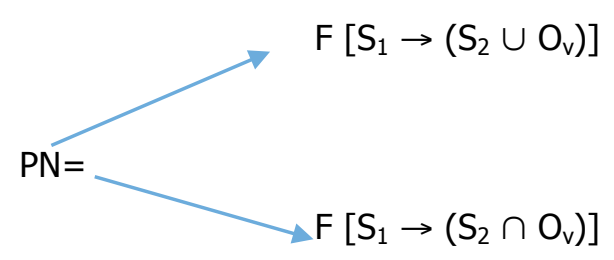

Legenda:

$\mathrm{PN}=$ programa narrativo

$F=$ função

$\mathrm{S}_{1}=$ sujeito de fazer

$\mathrm{S}_{2}=$ sujeito de estado

$\cup=$ disjunção

$\cap=$ conjunção

$\mathrm{O}_{\mathrm{v}}=$ objeto-valor

Fonte: Elaborado pelo autor

Pelos enunciados de fazer opera-se a passagem de um estado para outro, de conjunção para disjunção com o objeto-valor ou vice-versa. Os enunciados de fazer são, portanto, enunciados responsáveis pela transformação de estados. Os enunciados de estado situam-se no tempo e no espaço; os de fazer, por corresponderem a transformações de estado, devem ser interpretados como passagem de um lugar para outro ou de um tempo para outro. A narratividade deve ser entendida como a sucessão de transformações do sujeito de estado por um sujeito de fazer e também pela sucessão de 
contratos que se estipulam e se quebram entre sujeitos (destinador e destinatário).

Essa sucessão de transformações e rupturas vai constituir um percurso narrativo. Para executar esse percurso (uma performance), é pressuposto que o sujeito disponha de uma competência, um saber-fazer, que lhe é dado pelo destinador-manipulador, que determina quais os valores visados pelo sujeito, transformando-o num sujeito de fazer que, em relação ao destinador, será o destinatário. A relação que se estabelece entre destinador e destinatário é a de um contrato fiduciário, em que o destinador exerce um fazer persuasivo, visando à adesão do destinatário, para fazê-lo, ao realizar um fazer interpretativo, crer verdadeiros o objeto, o discurso e o próprio destinatário. A semiótica apresenta uma tipologia da manipulação, que pode ser exercida por provocação, por sedução, por tentação e por intimidação. Na provocação e na sedução persuade-se pelo saber; na intimidação e na tentação, pelo poder.

Os programas narrativos podem ser de aquisição ou de privação de valores. No primeiro caso, o sujeito de estado entra em conjunção com um objeto-valor; no segundo, ocorre a disjunção. Os programas narrativos de aquisição ou privação podem ser transitivos, quando o sujeito de fazer é diferente do sujeito de estado, ou reflexivos, quando o sujeito de fazer é igual ao sujeito de estado. Dessa forma, esquematizando tem-se o seguinte:

\section{Programas narrativos de aquisição e de privação}

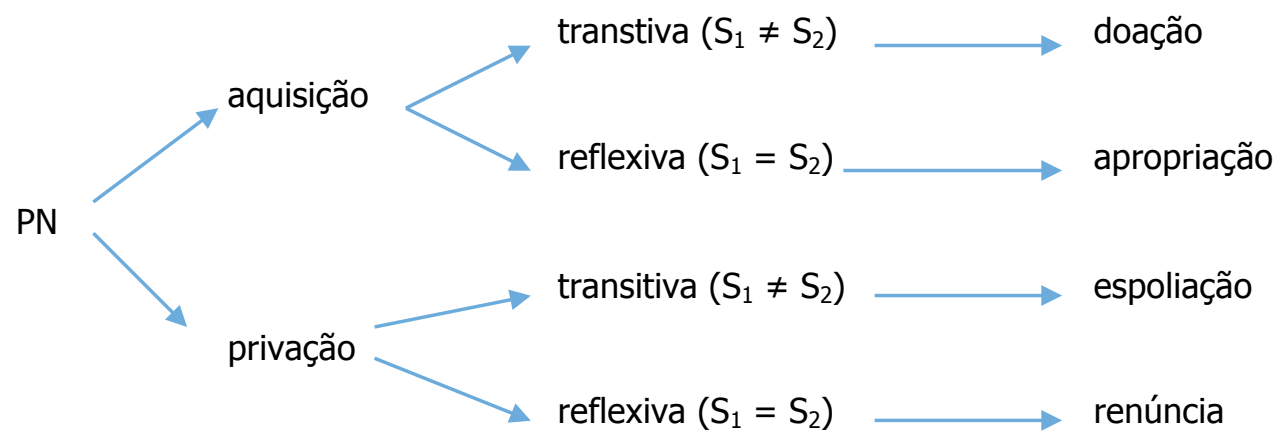

Legenda: Tipos de programas narrativos

Fonte: Elaborado pelo autor 
Para Barros (1988, p. 33),

\begin{abstract}
Todo programa narrativo projeta um programa correlato, ou seja, o programa de doação corresponde, em outra perspectiva, ao programa de renúncia, da mesma forma que o programa de apropriação é concomitante ao programa de espoliação. O desdobramento e a correlação de programas levam a ler a transformação de estados como transferência de objetos-valor e como comunicação de objetos entre dois sujeitos que, por meio deles, se relacionam.
\end{abstract}

No nível discursivo, a semântica cuida do percurso temático e do revestimento figurativo dos temas e é, para Fiorin (2000), "o campo das determinações inconscientes". A semântica discursiva assume papel relevante na medida em que é por ela que se manifestam de forma mais cabal as determinações históricas e ideológicas. A conversão dos percursos narrativos em percursos temáticos e figurativos cabe ao sujeito da enunciação, que, com isso, confere coerência semântica a seu discurso, criando efeitos de realidade, na medida em que garante a adequação entre discurso e mundo. A reiteração de temas e de figuras na totalidade da cadeia do discurso vai constituir as isotopias (temáticas ou figurativas). Quanto à sintaxe, ela trata das relações entre enunciação e discurso e das relações entre enunciador e enunciatário, especialmente dos recursos argumentativos de que se vale o primeiro para levar o segundo a um crer e a um fazer.

Saliento que os três níveis do percurso gerativo do sentido têm caráter apenas operacional, a fim de permitir ao analista descobrir as invariantes que regem o discurso e que cada nível funciona como uma complementação do sentido do nível que o antecede. Assim, o analista pode ir da significação mais simples, presente no nível fundamental, dada pela oposição de dois contrários, até a significação mais complexa, presente no nível discursivo, num percurso ascencente. Nesse caso, segundo Fontanille (2012), o ponto de vista é o do discurso; ou, ao contrário, num percurso descendente, no qual o ponto de vista é o do texto. Ainda segundo o semioticista francês, 
Portanto, o ponto de vista do discurso seria, no sentido restrito, gerativo, já que parte das estruturas do conteúdo mais gerais para recuperar progressivamente a diversidade e as particularidades da expressão. Em suma, ele seria o ponto de vista que se empenharia em nos apresentar uma representação da produção semiótica. $O$ ponto de vista do texto, em contrapartida, poderia ser qualificado como hermenêutico, pois ele é dirigido pela busca de uma explicação e de uma intencionalidade que seriam subjacentes aos fatos textuais propriamente ditos. Esse seria, então, o ponto de vista que nos daria uma interpretação semiótica (FONTANILLE, 2012, p. 90).

O percurso gerativo do sentido, como assinalei, diz respeito ao nível do conteúdo, abstraindo sua expressão, seja linguística, gestual, pictórica. Ultimamente, a partir dos estudos de Floch sobre o texto visual, a semiótica tem se voltado também à análise do plano da expressão e não só de textos visuais, mas também de textos verbais, já que nos textos poéticos ele é constitutivo do sentido, por meio do sistema semissimbólico.

Assinalo que a passagem de um nível a outro do percurso gerativo realiza-se por conversão, isso significa que não há ruptura entre um nível e outro. Na passagem do nível fundamental para o nível narrativo, as axiologias presentes no primeiro são agora assumidas por um sujeito. Por isso se diz que o nível narrativo corresponde a uma antropomorfização, em que sujeitos de estado são modificados por sujeitos de fazer, entrando em junção com objetos investidos de valor, simulando, portanto, a ação do homem no mundo. Nesse sentido, é importante lembrar as palavras de Barros (1988, p. 27).

\footnotetext{
Pela conversão semântica, os valores virtuais, isto é, ainda não assumidos por um sujeito na instância fundamental, são selecionados e atualizados na instância narrativa. A atualização realiza-se em duas etapas: inscrição de valores em objetos, que se tornam objetos-valor, e a junção dos objetos-valor com os sujeitos. Os sujeitos axiológicos virtuais convertem-se, dessa forma, em valores ideológicos, entendidos como valores assumidos por um sujeito, a partir de seleção no interior de sistemas axiológicos.
}

Para que se possa empreender a análise discursiva dos textos, é necessário que se pense a enunciação como instância que produz os discursos. Para Greimas e Courtés (2012, p. 167), "[...] a enunciação é o lugar de 
exercício da competência semiótica, é ao mesmo tempo a instância da instauração do sujeito (da enunciação)."

Para Fiorin (2001, p. 43), "os mecanismos de instauração de pessoas, espaços e tempos nos enunciados são dois: a debreagem e a embreagem [...]." O mecanismo pelo qual se instala no texto um eu-aqui-agora é denominado debreagem, que pode ser enunciativa, isto é, o sujeito da enunciação deixa marcas linguísticas no enunciado que produz (enunciação enunciada). Nesse caso, há um simulacro da enunciação, com efeito de sentido de subjetividade; ou enunciva, em que há o apagamento do sujeito da enunciação, o que confere ao texto marcas de objetividade, na medida em que o efeito de sentido é de um afastamento da instância da enunciação (discurso-enunciado). Objetividade e subjetividade devem aqui ser entendidas na perspectiva dada por Benveniste, qual seja, de efeitos de sentido que o enunciador mantém com a enunciação. Fiorin referindo-se à debreagem afirma que ela:

[...] consiste, pois, num primeiro momento, em disjungir do sujeito, do espaço e do tempo da enunciação e projetar no enunciado um não-eu, um não-aqui e um não-agora. Como nenhum eu, aqui ou agora inscritos no enunciado são realmente a pessoa, o espaço e o tempo da enunciação, uma vez que estes são sempre pressupostos, a projeção da pessoa, do espaço e do tempo da enunciação no enunciado é também uma debreagem (FIORIN, 2001, p. 43) (grifos do autor).

A embreagem é outra forma de instalação das categorias da enunciação no enunciado. Nela, ocorre o inverso da debreagem: há um efeito de retorno à enunciação, com a consequente neutralização das categorias de pessoa, espaço e tempo. A embreagem, portanto, pressupõe uma debreagem anterior.

Segundo Fiorin (2001, p. 48),

[...] a embreagem é 'o efeito de retorno à enunciação', produzido pela neutralização das categorias de pessoa e/ou espaço e/ou tempo, assim como pela denegação da instância do enunciado". Apresenta-se como uma operação de retorno de formas já debreadas à enunciação e cria a ilusão de identificação com a instância da enunciação. A enunciação finge recuperar as formas que projetou para fora de si. 
Outro ponto essencial para se proceder à análise discursiva dos textos é entender a articulação entre discurso e narrativa, na medida em que o nível discursivo dos textos se sustenta nas estruturas narrativas.

Quanto às paixões, elas devem ser tomadas como modalizações do sujeito de estado, que se relaciona com o destinador numa relação comunicativa e com o objeto-valor numa relação transitiva, mantendo laços passionais tanto com o destinador quanto com o objeto-valor. Três são as formas de existência do sujeito:

[...] existência semiótica, determinada pela relação sintática entre sujeito e objeto (definição topológica de narrativa como lugar de circulação de valores); existência semântica, caracterizada pela relação do sujeito com o valor (narrativa como sintaxe de comunicação entre sujeitos); existência modal, em que o sujeito se define pela modalização do seu ser e assume papéis patêmicos (narrativa como sintaxe modal). Os 'estados de alma' estão relacionados à existência modal do sujeito, ou seja, o sujeito segue um percurso, entendido como uma sucessão de estados passionais, tensos-disfóricos ou relaxados-eufóricos (BARROS, 1988, p. 62) (grifo do autor).

Greimas e Fontanille (1993) também insistem que o sujeito afetado pela paixão será sempre um sujeito de estado, ainda que possa ser responsável por um fazer, como no remorso ou no furor. As paixões podem ser simples, quando o sujeito de estado é modalizado pelo /querer-ser/, ou complexas, nas quais ocorrem várias organizações de modalidades. Aquilo que falta funciona como despertar afetivo ao sujeito de estado, que tem sua sensibilidade ativada de modo mais ou menos intenso. A intensidade das paixões pode acarretar, em determinadas sociedades, efeitos moralizadores, por exemplo, a excessiva preocupação com a aparência caracteriza a vaidade; o medo excessivo caracteriza o terror; o apego excessivo a bens materiais leva a avareza, se os bens são de valor irrisório, à mesquinharia. Assim, um sujeito que se pauta pela economia tem avaliação positiva, enquanto que para o avaro a avaliação é negativa. 
Como os sujeitos de estado dos textos analisados neste artigo são modalizados pelo desejo, uma paixão simples, limito-me a falar, em rápidas pinceladas, apenas sobre essa paixão.

Do Dicionário Houaiss, recorto a primeira acepção de desejo, que é a que interessa para os fins desse artigo:

1. aspiração humana de preencher um sentimento de falta ou incompletude.

Como se vê, o desejo configura o sujeito de estado disjunto de um objeto-valor com o qual pretende entrar em conjunção, portanto o desejo é configurado pela falta, pela incompletude.

Dados os limites deste artigo, a análise do corpus foi feita basicamente respaldada na semiótica standard. Os aspectos relativos aos estados de alma e à tensividade tiveram importância subsidiária ao foco da investigação, que recaiu principalmente sobre o percurso gerativo do sentido dos textos estudados.

\section{"Cicatriz": análise semiótica}

Para a semiótica, na esteira de Saussure, falar em sentido é falar em diferença já que o sentido é sempre dado por uma relação. Assim, o sentido de cozido decorre de sua diferença com cru (cozido é aquilo que não é cru). Mesmo o sujeito presente no nível narrativo não tem por si só existência semântica, nem semiótica. Sua existência está condicionada a uma relação transitiva que o liga a um objeto. Anteriormente à junção com um objeto, é apenas um sujeito virtual.

O sentido de talhado no poema decorre de sua relação com o termo negativo (não-talhado), ou seja, inteiro, completo. Por isso, vamos considerar que, no nível fundamental, o poema articula-se a partir de oposições como /talho vs. inteiro/, /completo vs. incompleto/, /moribundo vs. vivente/; /mudo vs. com voz/, que poderíamos reunir nas relações semânticas fundamentais /totalidade vs. unidade/ e /morte vs. vida/. Um corpo talhado pressupõe necessariamente um corpo que não foi objeto de talho, portanto inteiro, 
completo. Nesse nível mais profundo, temos a negação da parte e a afirmação do todo, a negação da morte e a afirmação da vida.

O nível fundamental é marcado, pois, pela tensividade entre o talho e o inteiro, entre o incompleto e o completo, entre a morte e a vida em que os primeiros são mais tensos e os segundos mais relaxados. As categorias semânticas fundamentais podem ainda ser axiologizadas na categoria /eufórico vs. disfórico/. Euforia e disforia dizem respeito ao modo como um ser vivo se sente em relação ao meio ambiente. Será eufórica, quando em conformidade e disfórica quando em não-conformidade. Para Tatit (2001), na euforia há tendência à noção de continuidade, enquanto na disforia a tendência é para a suspensão da continuidade. O semioticista afirma ainda que "[...] é considerado eufórico, em princípio, tudo que leva à junção com os valores desejados e, portanto, à neutralização das tensões" (TATIT, 2001, p.100). Em "Cicatriz", o completo e a vida são eufóricos; o incompleto e a morte são disfóricos.

No nível fundamental são valores virtuais, pois ainda não estão relacionados a um sujeito. $O$ poema trata, pois, da passagem do talhado para 0 inteiro, do esfacelamento para a integralidade, do que está para morrer para o que começa a viver, ou seja, o percurso é do disfórico para o eufórico. "Cicatriz" é, pois, um texto euforizante.

No nível narrativo, espaço privilegiado da troca de valores, temos um sujeito de estado, disjunto de um objeto-valor, a completude. Do ponto de vista passional, esse sujeito de estado é modalizado por um /querer-ser/. A paixão que caracteriza esse sujeito é o desejo, entendido aqui como o preenchimento de uma incompletude, de um vazio. O percurso narrativo desse sujeito, ou seja, o encadeamento sintático de programas narrativos será, pois, levá-lo a entrar em conjunção com esse objeto-valor, que o levará ao estado de completude. Para isso, é necessário que um destinador manipule-o, atribuindo-lhe uma competência, isto é, um querer, um poder, um dever e um saber fazer. Esse actante é o destinador, que exerce a função de qualificar o sujeito de estado para realizar uma performance, no caso entrar em conjunção com o objetovalor. No dizer de Barros (1988, p. 18), "[...] destinador é aquele que 
determina a competência e os valores do sujeito que age, aquele que, em suma, estabelece as regras do jogo." No poema, o destinador é representado pelo corpo talhado e o sujeito de estado quer, pode, deve e sabe entrar em conjunção com o objeto-valor completude.

O destinador propõe ao destinatário, agora transformado em sujeito da ação, um contrato e espera que ele cumpra esse contrato. No caso de "Cicatriz", é recuperar a completude. Caso cumpra, será sancionado positivamente; se não cumprir, a sanção será negativa. A sanção, como se vê na última estrofe, é positiva, já que o eu talhado e moribundo entra em conjunção com os objetos-valor completude e vida e "sobe o pano", isto é, começa uma nova performance, na qual "cessa o pranto", isto é, com interrupção do sofrimento e "nasce o encanto", vale dizer, um novo ser, inteiro e completo, vai surgir dos talhos do corpo dilacerado, o que é causa de fascínio e prazer.

Esse programa narrativo do sujeito talhado em busca da inteireza toma sensorialidade e concretude no nível discursivo por meio de uma semântica e de uma sintaxe discursivas. A semântica é representada pelos temas e figuras que se encadeiam dando coerência ao texto e são ainda o lugar privilegiado em que se manifestam mais claramente as determinações do enunciador. Destaco ainda que as figuras são responsáveis por dar corpo e sensorialidade ao texto. Aquele eu disjunto agora se encarna, deixa de ser um actante para ser um ator do enunciado.

Uma das características da poesia de Jessyca Pacheco é o efeito de vertigem que causam seus poemas, na medida em que se manifestam nos limites do sensível e do inteligível, buscando uma epifania, no sentido de que a realidade é apreendida pelo inesperado e simples.

Dos temas presentes em "Cicatriz" já falei: estão ligados à dilaceração, ao aniquilamento do ser e são concretizados por figuras como "corpo talhado", "mudo", "cansado", "grassento", "sombras". Como em outros poemas de Matéria derradeira, a autora mescla a sensorialidade em sinestesias várias, como "sorrir silencioso", "sussurros líquidos" ("Gato no escuro", p. 16), "o gosto 
do gozo cúmplice silencioso" ("O corpo", p. 19), "cheiro e sons presentes" (Sombras, p.24), "sussurros tatuados no meu corpo" ("Caíram", p. 26), "tateio sons que reverberam em uníssono" ("Sobre manhãs", p. 32), "sonoridade disforme" ("Somos a instância máxima", p. 39).

A sintaxe discursiva relaciona-se à enunciação. No poema, instala-se um eu cuja função é narrar os acontecimentos, filtrando o discurso. Esse actante narrativo que denominamos narrador é uma delegação do enunciador, que pelo mecanismo da debreagem actancial o instala no texto. Enquanto enunciador e enunciatário pertencem ao primeiro nível da enunciação, narrador e narratário correspondem a um segundo nível hierárquico da enunciação, são actantes da enunciação enunciada.

Esclareço que "Cicatriz" é um poema que se configura em suas três primeiras estrofes como uma enunciação enunciada, o que configura um efeito de subjetividade. Há um eu instalado no texto cujas marcas se evidenciam na forma verbal ostento, imperfectiva cursiva, o que, segundo Castilho (2010, p. 421) "[...] apresenta o estado de coisas em seu pleno curso, sem referência às fases inicial e final". Este eu é instalado por um procedimento denominado debreagem que, para Barros (2003, p. 85) "[...] é a operação pela qual a enunciação projeta os actantes e as coordenadas espácio-temporais do discurso, utilizando, para tanto, as categorias da pessoa, do espaço e do tempo". Esse eu terá, entre outras, a função de narrar os fatos. Entre as funções do narrador, destaco três:

a) a função narrativa (o narrar propriamente dito): $o$ caminhar lento $e$ grassento do corpo talhado e mudo;

b) indicar a direção do narrado (função metanarrativa): que vai dos passos leves do caminhar ao prazer leviano;

c) atestar a relação afetiva do narrador com o narrado: a perda, 0 aniquilamento.

Esse narrador que se manifesta na estrutura discursiva é a assunção de um sujeito presente na estrutura narrativa. Sujeito cindido, na medida que está despossuído de um objeto-valor, o corpo. Corpo pressupõe inteireza, unidade, 
completude, na medida em que ele é talhado, deixa de existir como unidade primitiva. O que se tem são fragmentos de corpo, ou novos corpos que não se confundem mais com o corpo original. No nível narrativo, temos a busca desse sujeito pelo retorno à inteireza, pois se o corpo está talhado é pressuposto que esteve inteiro. Assim, o percurso narrativo do sujeito é: corpo inteiro $\Rightarrow$ corpo talhado $\Rightarrow$ corpo inteiro.

A enunciação, além de instalar um sujeito, instala também por debreagem um tempo, que pode ser o da enunciação (o agora), ou não concomitante à enunciação (o então). $O$ tempo do poema é o agora, o presente (ostento). Trata-se de um presente contínuo, não um presente pontual e descontínuo, na medida em que, para o narrador, este presente traz em si a marca de um passado recente que ainda vive na memória e a expectativa de um futuro próximo, a antevisão do momento seguinte.

Para o filósofo alemão Husserl (1994), esse presente contínuo é chamado de campo de presença ou presente vivo. O filósofo o compara ao som da melodia. A melodia que ouvimos (presente) contém em si a retenção, as notas que a precederam e que ainda estão na memória e, portanto, ainda não é um passado, é a protensão do futuro próximo, a expectativa do porvir, portanto ainda não é futuro. $O$ tempo do poema é esse: um fluxo contínuo de um presente que incorpora um passado e um futuro. Esse passado, no entanto, é mudo na medida em que existe apenas como retenção na memória do eu, não sendo exteriorizado; ao contrário, como assinalarei adiante, do futuro, que será enunciado. Do ponto de vista do narratário, a leitura do poema é percebida em três fases:

a) fase 1: 0 ato presente da leitura, que cria uma impressão;

b) fase 2: a retenção do que foi percebido sensorialmente;

c) fase 3: uma leitura de outros poemas da autora, na qual ainda terá na consciência o poema "Cicatriz".

Como mostrarei adiante, na leitura de "Fragmentos" reavivam-se as impressões percebidas em "Cicatriz". Detenho-me na última estrofe. Chamo a atenção para o fato de, ao contrário das anteriores, termos uma debreagem 
enunciva (discurso-enunciado). Há um apagamento do eu, ganhando os dois versos finais um sentido de objetividade. 0 movimento do poema é então do interior para o exterior, caracterizando a objetivação do eu.

Esse movimento para fora está presente em outros textos da autora, como se pode observar pelo início do poema "Pausa": "algo me sacode para fora". Chamo a atenção ainda para a aspectualização. Como assinalei, nas estrofes anteriores o poema se construía em torno do imperfectivo, vale dizer, há um início (ostento), mas não há um desfecho. Trata-se de um imperfectivo cursivo: o processo é tomado não no seu início nem no seu fim, mas em sua duração. Na última estrofe, o processo verbal é perfectivo (sobe, cala-se, nasce), vale dizer, o processo é dado como acabado, ou seja, o início coincide com seu término, "tornando irrelevantes as fases de seu desenvolvimento" (CASTILHO, 2010, p. 419).

Apoiado ainda em Castilho (2010), lembro que o perfectivo ocorre nos segmentos das narrativas em que o narrado é o evento central. $E$ o evento central do narrado é "Sobe o pano, cala-se o pranto, nasce o encanto". Uma sequência de três orações justapostas, em que se invertem a ordem natural dos termos, na medida em que os sujeitos das orações são deslocados para depois dos verbos, dando, portanto, maior relevância aos processos (subir, calar-se e nascer) do que aos sujeitos desses processos. De certa forma, esses processos dispõem-se em uma gradação ascendente cujo clímax é representado por nascer.

Concluindo essa análise, posso afirmar que o poema é a negação da dilaceração do corpo e a afirmação de um processo gradativo que levará ao nascimento de um eu pleno, inteiro, novo, diferente do eu inteiro que existia antes do talho, do dilaceramento. Esse eu, que ainda não se completou, disfarça as cicatrizes, as dores, as angústias, obtendo o prazer de ser (ou ao menos fingir ser), algo que não pode voltar a ser; pois, quando ocorre a quebra, não há a possibilidade de retorno ao que se foi.

\section{"Fragmentos": análise semiótica}


"Fragmentos" retoma o tema presente em "Cicatriz" e em outros textos de Matéria derradeira: o sujeito cindido. A palavra fragmento tem sua origem no latim, a partir do radical frang-, primeira pessoa do singular do verbo frangere, que significa 'quebrar, despedaçar, fraturar, partir, rasgar, dilacerar, esfarrapar'. Desse radical, também provém em português o adjetivo frágil, que significa 'o que se espedaça ou se quebra facilmente'. Portanto, fragmento é o resultado do esfacelamento de algo que se partiu, porque era frágil. Essa é a pista que nos leva ao que há de mais profundo e abstrato no texto, a oposição semântica fundamental /totalidade vs. unidade/, que também aparece em "Cicatriz". Nesses dois textos e nos demais de Matéria derradeira, as oposições semânticas de base podem ser englobadas na oposição /contínuo vs. descontínuo/, em que se nega a descontinuidade, valor disfórico, e afirma-se a continuidade, valor eufórico. Ler a poesia de Jessyca Pacheco é empreender um percurso que leva sempre à integralidade, à completude, ou pelo menos à tentativa de restabelecê-las.

Chamo a atenção para o fato de que essas categorias do nível fundamental e apresentadas no quadrado semiótico por meio de uma negação e de uma asserção, constituem um modelo de previsibilidade. A cada texto esses valores fundamentais são assumidos por sujeitos que, no nível narrativo, realizam percursos distintos e, no nível discursivo, apresentam figurativização diferente. Retomo o que disse no início deste artigo: os textos de Matéria derradeira constituem um todo discursivo e assim podem ser lidos, no entanto cada texto em si é um discurso autônomo que deixa na memória o texto que o antecedeu e projeta o texto que segue, o presente vivo ou campo de presença de que fala Husserl (1994). Assim, se lê a poesia de Jessyca Pacheco, como na audição de uma melodia. O "vazio" entre um texto e outro é pleno de sentido, porque é o espaço da retenção e da protensão.

No nível narrativo, temos um sujeito de estado que está em disjunção com o objeto-valor (sua casa, com tudo que nela contém). O sujeito disjunto pressupõe que ele estivesse em conjunção com o objeto-valor. $O$ sujeito de fazer que realiza essa disjunção é figurativizado no texto como um incêndio. 0 
percurso desse sujeito de estado será, pois, entrar em conjunção com o objetovalor perdido. Trata-se do ponto de vista da semiótica das paixões de um sujeito modalizado pelo /querer-ser/ e, assim como em "Cicatriz", a paixão que o caracteriza é o desejo. Para realizar essa performance, necessitará de uma competência (um querer, um saber, um dever e um poder fazer), que lhe será dada por sujeito de fazer (um destinador). No entanto, como recuperar esse objeto-valor se ele foi destruído pelo incêndio? O objeto será investido de outros valores, no caso, a continuidade, a integralidade, a completude. $\mathrm{O}$ sujeito de estado está disjunto de tudo, até de um nome que o individualize, não há iconização desse sujeito e, portanto, não há o efeito de ilusão referencial. O nome, como se sabe, tem função individualizante. $O$ sujeito não é mais indivíduo, ou seja, aquilo que não se divide. Desfez-se no descontínuo, é também fragmento, assim como os restos do incêndio.

No nível discursivo, aquele que é mais concreto e superficial, em que se percebem mais nitidamente as determinações, há um actante, o observador, que tudo sabe, e que acompanha esse sujeito, agora um ator discursivo, em seu percurso na transformação do inteiro (indivíduo) em fragmento (cinzas, decorrentes das chamas, da "labareda indomável"). Quanto à sintaxe discursiva, como assinalei, temos um observador que vê de fora essa fragmentação do sujeito e seu percurso em busca da completude. A debreagem actancial é enunciva, temos um discurso-enunciado, o que confere efeito de sentido de objetividade ao narrado. Pela enunciação, instala-se também um tempo, que é do sistema do passado.

O observador narra um incêndio que ocorreu num determinado domingo perdido no tempo e no espaço usando o imperfeito, portanto, o que se narra não é um incêndio que acabou, mas um incêndio em sua duração, um incêndio que ocorre diante das vistas do observador, da personagem e de nós, leitores.

Quanto à aspectualização, temos a predominância do imperfectivo cursivo, o que equivale dizer que os processos não são vistos nem em seu início, nem em seu término, mas em seu desenvolvimento, em sua duração: "...fina poeira cinza que caía...", "Seus ouvidos zuniam...", "pensava em como 
se livrar...", "As chamas aos poucos consumiam a cor e a forma de cada objeto...".

Fragmentos são, como disse, pedaços, farelos daquilo que se partiu porque era frágil, quebrável. A partir do momento que o inteiro se despedaçou, não há como juntar esses fragmentos para recompô-lo. Mas, como ocorre em outros textos da autora, ela faz tentar renascer o todo (o indivíduo) a partir das partes (fragmentos), isso porque os fragmentos não são apenas o que se destruiu do incêndio, mas também são pessoas que se aglomeram e "as aglomerações desencantam", porque para ela o prazer está na solidão e é nela que reside a individualidade, o eu profundo.

\section{Considerações Finais}

A partir da desmontagem de dois textos, "Cicatriz" e "Fragmentos", intentei mostrar que os textos de Jessyca Pacheco se constroem a partir da axiologia /contínuo vs. descontínuo/, presente em sua estrutura profunda, sendo o primeiro eufórico e relaxado e o segundo disfórico e tenso. Do ponto de vista das operações lógicas, nega-se o descontínuo e afirma-se o contínuo, que é assumido no nível narrativo por um sujeito, tornando-se valor ideológico. Isso significa que os textos são euforizantes na medida em que vão do disfórico para o eufórico. Em termos da semiótica tensiva, são textos que caminham da tensão para a distensão.

Os sujeitos narrativos se corporificam no nível discursivo em sujeitos fragmentados, cindidos e, do ponto de vista da semiótica das paixões, são modalizados pelo desejo, paixão presente em quase todos os textos da autora, num gradiente que vai do desejo menos intenso ao mais tenso, dependendo do objeto do desejo. Assim, em certos poemas, é o desejo de recuperar a integralidade perdida do ser como em "Cicatriz" e "Fragmentos". Em outros, é a busca do prazer, da satisfação física, do gozo. Como se busca a completude a partir de fragmentos, é pressuposto que, para ser completo, se entre em conjunção com o gozo. 
As figuras são o topos onde o ideológico se manifesta mais claramente no discurso. Um levantamento das figuras de todos os poemas de Matéria derradeira, mostra que essa fragmentação é a do corpo que está talhado. Não é sem razão que as isotopias figurativas são marcadas por metonímias relativas a partes do corpo como: o olhar e a cona (p.12), os bustos (p.16), a boca, a pele, a língua (p.17), as pernas, os quadris e o ventre (p.18), os fios de cabelo, o seio (p.19), os dedos, o colo, o pescoço, a orelha, os pés, os lábios (p.20), as unhas, os dentes (p.21), as costas (p.22), o sexo (p.23), o rosto (p.24), as coxas (p.26), os lábios (p.27), as mãos (p.31), as papilas (p. 33), os pulmões, o músculo (p.40), os cabelos (p.41), a face (p.42), os ouvidos, os olhos (p.43).

As figuras de palavras superpõem dois planos: diz-se uma coisa no enunciado e outra na enunciação, portanto, as isotopias presentes no enunciado devem ser lidas de forma mais geral e abstrata como isotopias da enunciação. Assim, as isotopias figurativas do enunciado, expressas por metonímias como cona, boca, pele, língua, quadris, seios, dedos, lábios, na enunciação correspondem a isotopias temáticas ligadas ao prazer, à excitação, ao gozo.

Portanto, posso afirmar que a isotopia figurativa que reveste o tema da dilaceração do corpo é uma das possibilidades de leitura dos textos que constituem o livro Matéria derradeira. Essa leitura, que chamo de sintagmática, concentra-se no descontínuo, no fragmento. A ela, superpõe-se uma leitura paradigmática, em que, a partir da negação do descontínuo, afirma-se a continuidade, ou como diz a própria Jessyca Pacheco no último poema do seu livro: "Restabeleço a ordem ao / Criar o caos no corpo, ao / Navegar dentro de outros".

\section{Referências}

BARROS, Diana Luz Pessoa de. Teoria do discurso: fundamentos semióticos. São Paulo: Atual, 1988.

BARROS, Diana Luz Pessoa de. Teoria semiótica do texto. 4. ed. São Paulo: Ática, 2003. 
CASTILHO, Ataliba T. de. Nova gramática do português brasileiro. São Paulo: Contexto, 2010.

FIORIN, José Luiz. Linguagem e ideologia. São Paulo: Ática: 2000.

FIORIN, José Luiz. As astúcias da enunciação: as categorias de pessoa, espaço e tempo. 2. ed. São Paulo: Ática, 2001.

FONTANILLE, Jacques. Semiótica do discurso. São Paulo: Contexto, 2012.

GREIMAS, Algirdas Julien; FONTANILLE, Jacques. Semiótica das paixões: dos estados de coisas aos estados de alma. São Paulo: Ática, 1993.

GREIMAS, Algirdas Julien; COURTÉS, J. Dicionário de semiótica. 2. ed. São Paulo: Contexto, 2012.

HUSSERL, Edmund. Lições para uma fenomenologia da consciência interna do tempo. Lisboa: Imprensa Nacional-Casa da Moeda, 1994.

PACHECO, Jessyca. Matéria derradeira. São Paulo: Córrego, 2015.

TATIT, Luiz. Análise semiótica através das letras. São Paulo: Ateliê, 2001. 